\title{
Composition and production of thiol constituents induced by cadmium in the marine microalga Tetraselmis suecica
}

\author{
Mónica Pérez-Rama, Enrique Torres Vaamonde, Julio Abalde Alonso \\ Laboratorio de Microbiología, Facultad de Ciencias, Universidade da Coruña, 15008 A \\ Coruña, Spain
}

Environmental Toxicology and Chemistry, Volume 25, Issue 1, January 2006, Pages $128-136$

Manuscript Received: 12 April 2005; Manuscript Accepted: 27 June 2005

This is the peer reviewed version of the following article:

Pérez-Rama, M., Torres, E. and Abalde, J. (2006), Composition and production of thiol constituents induced by cadmium in the marine microalga Tetraselmis suecica. Environmental Toxicology and Chemistry, 25: 128-136. doi:10.1897/05-252R.1

which has been published in final form at http://dx.doi.org/10.1897/05-252r.1 This article may be used for non-commercial purposes in accordance with Wiley Terms and Conditions for Self-Archiving."

\footnotetext{
Abstract

Time course of intracellular levels of different thiols (phytochelatins, desglycylphytochelatins, glutathione, $\gamma$-glutamylcysteine $[\gamma$-Glu-Cys], and cysteine) were studied in the microalga Tetraselmis suecica exposed to different cadmium concentrations for 8 d. The cadmium concentrations assayed were 3, 7.9, 15, and $30 \mathrm{mg} / \mathrm{L}$. Contents of thiol compounds synthesized by this microalga changed with cadmium concentration and with time of exposure. Cysteine concentrations increased significantly compared with those of $\gamma$-Glu-Cys and glutathione in cultures containing 7.9, 15, and $30 \mathrm{mg} / \mathrm{L}$. The
} 
increase in the amount of glutathione was significant only in cells exposed to the higher cadmium concentrations (15 and $30 \mathrm{mg} / \mathrm{L}$ ). Nevertheless, in all the cadmium concentrations assayed, $\gamma$-Glu-Cys levels were constant. A rapid increase in phytochelatins was observed with increased cadmium concentration during the first days of culture. The type of phytochelatins (number of subunits) also was dependent on the concentration of cadmium. The rate of $(\gamma \text {-Glu-Cys })_{3}$-Gly accumulation was higher than those of other types of phytochelatins throughout the culture in cells exposed to 3 , 15 , and $30 \mathrm{mg} / \mathrm{L}$. However, in cultures treated with $7.9 \mathrm{mg} / \mathrm{L},(\gamma-\text { Glu-Cys })_{4}-$ Gly increased substantially after $8 \mathrm{~d}$ of culture, exceeding the amount of ( $\gamma$-Glu-Cys) $)_{3}$-Gly. Cultures exposed to the higher cadmium concentrations (15 and $30 \mathrm{mg} / \mathrm{L}$ ) showed a decrease in phytochelatins after 4 and $3 \mathrm{~d}$ of culture, respectively, whereas an increase in cysteine and glutathione occurred at the same time. A rapid decrease in phytochelatins also was measured when cells were placed into cadmium-free medium. This decrease is consistent with a degradation of the phytochelatins.

\section{Keywords}

Thiols; Phytochelatins; Cysteine; Cadmium; Microalga

\section{INTRODUCTION}

Different environmental studies have shown that coastal areas often are affected by cadmium pollution. This pollution causes loss of biological diversity and increased bioaccumulation and magnification of cadmium in the food chain. The survival capacity of different aquatic organisms, including phytoplankton, depends on the presence of specific responses that prevent the toxicity of this metal.

Microalgae have developed different resistance mechanisms, such as adsorption of metal ions to cell wall components, excretion of organic compounds forming extracellular complexes with the metal ions, and production of metal ion chelators either in the cytosol or at intracellular level [1].

Phytochelatins (small, thiol-containing peptides) are assumed to act as intracellular chelators $[\mathbf{2 , 3}$. These molecules are oligo- and polypeptides with the amino acid structure $(\gamma$-glutamylcysteine [ $\gamma$-Glu-Cys)]n-Gly; also abbreviated as $\gamma$ - 
$\mathrm{EC} n \mathrm{G})$. Phytochelatins with $n$ ranging from 2 to 11 have been described [4,5]. Although glycine is the most common terminal amino acid, glutamic acid [6], serine [7], and $\beta$ alanine [8] have been found instead of glycine in several species. Moreover, the terminal amino acid does not appear in desglycyl-phytochelatins [9]. In these molecules, cadmium is chelated throughout coordination with the thiol group of cysteine.

Phytochelatins are synthesized enzymatically from the tripeptide glutathione (GSH) by a $\gamma$-glutamyl-cysteinyl-dipeptidyl transpeptidase (phytochelatin synthase) $[10,11]$. The enzyme cleaves the terminal glycine from one GSH and catalyzes the transfer of the $\gamma$-glutamyl-cysteinyl-dipeptidyl to the amino terminus of another GSH that acts as acceptor to form the $n=2$ oligomer; hence, the chain grows by binding additional $\gamma$-Glu-Cys moieties to the phytochelatin peptide chain.

Previous synthesis of GSH, carried out in two steps involving two enzymes, is necessary for the synthesis of phytochelatins. In the first step, $\gamma$-glutamylcysteine $(\gamma$ Glu-Cys) synthetase combines the amino acids glutamic acid and cysteine to form $\gamma$ Glu-Cys. Later, the enzyme GSH synthetase catalyzes the reaction between $\gamma$-Glu-Cys and the amino acid glycine to form GSH [4].

Therefore, GSH is the base unit of phytochelatins, and at the same time, cysteine is the main precursor of GSH via synthesis of $\gamma$-Glu-Cys. Cysteine biosynthesis is required under conditions of metal stress to allow increased biosynthesis of GSH and phytochelatins. Moreover, different reports have shown that cysteine also is involved in metal detoxification [12-14].

Once cadmium is chelated by phytochelatins, these complexes are carried toward the vacuolar system. Nassiri et al. $[\mathbf{1 5 , 1 6}]$ observed that the cadmium accumulated in the vacuoles of Tetraselmis suecica and Skeletonema costatum showed good correlation between cadmium, sulfur, and nitrogen. This suggests that phytochelatin-cadmium complexes can be sequestered in the lysosomal or vacuolar system.

Interest regarding the involvement of physiological responses in monitoring studies has been increasing. To understand the tolerance mechanism developed by phytochelatins, it is essential to know the dynamics of the synthesis and the stability of these molecules and their precursors. Few reports on the evolution of phytochelatins and their precursors, both with time of exposure and with different doses of cadmium in 
microalgal cells, have been printed $[\mathbf{3 , 1 7}]$. Thus, the goal of the present study was to examine the time course of synthesis, magnitude of response, and degree of polymerization of phytochelatins by $T$. suecica (a typical marine microalga) exposed to different cadmium concentrations. The intracellular concentrations of GSH, $\gamma$-Glu-Cys, and cysteine also were measured in response to metal stress. In the present study, a sensitive capillary electrophoresis technique was used to analyze phytochelatins and related thiols. This technique allows the quantification and characterization not only of phytochelatins but also of cysteine, $\gamma$-Glu-Cys, GSH, and other thiol peptides, such as desglycyl-phytochelatins, simultaneously (i.e., in the same run) [18]. Samples were derivatized previously with monobromobimane, a chromogenic compound that labels thiol groups and provides selectivity in the detection process.

Persistence of thiols in cultures (previously exposed to cadmium) transferred to a medium without metal also was monitored.

\section{MATERIALS AND METHODS}

\section{Chemicals and reagents}

All chemicals were of the highest purity available. Ortho-phosphoric acid $\left(\mathrm{H}_{3} \mathrm{PO}_{4}\right)$, boric acid $\left(\mathrm{H}_{3} \mathrm{BO}_{3}\right)$, hydrochloric acid $(\mathrm{HCl})$, sodium hydroxide $(\mathrm{NaOH})$, monobromobimane $\left(\mathrm{C}_{10} \mathrm{H}_{11} \mathrm{~N}_{2} \mathrm{O}_{2} \mathrm{Br}\right)$, sodium borohydride $\left(\mathrm{NaBH}_{4}\right)$, diethylenetriaminepentaacetic acid anhydride $\left(\mathrm{C}_{14} \mathrm{H}_{19} \mathrm{~N}_{3} \mathrm{O}_{8}\right)$, ethylenediaminetetraacetic acid (EDTA), lugol, and Tris (hydroxymethyl) amino methane (TRIS) were purchased from Sigma (St. Louis, MO, USA). High-performance liquid chromatography-grade methanol was purchased from Scharlau Chemie (Barcelona, Spain). Filters were obtained from Millipore (Millipore Ibérica, Madrid, Spain).

The different reagents and running buffers were prepared with Milli-Q ${ }^{\circledR}$ water obtained from a Milli Q Plus system (Millipore Iberica).

\section{Tetraselmis suecica culture conditions and cadmium treatment}

Cells of the marine microalga $T$. suecica (Kylin) Butch were grown in natural, enriched seawater medium with the addition of inorganic nutrients without EDTA and TRIS [19]. The seawater was passed through a 0.45-fxm Millipore filter and a charcoal 
column to eliminate organic chelating substances and, afterward, was sterilized at $121^{\circ} \mathrm{C}$ for $20 \mathrm{~min}$. The salinity of the seawater was $35 \%$, and the initial $\mathrm{pH}$ of the culture was 7.8. Cultures were maintained at $18 \pm 1{ }^{\circ} \mathrm{C}$ under a light intensity of 68 $\mu \mathrm{E} / \mathrm{m}^{2} / \mathrm{s}$ using cool fluorescent light with a 12:12-h light:dark cycle. Natural sterile air was constantly bubbled at a flow rate of $10 \mathrm{~L} / \mathrm{min}$.

Tetraselmis suecica was cultured for $8 \mathrm{~d}$ with cadmium concentrations of 3, 7.9, 15 , and $30 \mathrm{mg} / \mathrm{L}$. Initial cell density in the assays was $25 \times 10^{4}$ cells $/ \mathrm{ml}$. Control cultures without cadmium were included. Each experiment was carried out in triplicate.

The cadmium concentration corresponding to the median effective concentration (EC50) for this microalga was estimated previously [20] as $7.9 \pm 1 \mathrm{mg} / \mathrm{L}$ of cadmium after $6 \mathrm{~d}$ of exposure to this metal. Therefore, the cadmium concentration of $7.9 \mathrm{mg} / \mathrm{L}$ was selected for the assay, and two concentrations above (15 and $30 \mathrm{mg} / \mathrm{L})$ and one concentration below ( $3 \mathrm{mg} / \mathrm{L})$ also were assayed.

Growth of microalgal cultures was measured daily by counting culture aliquots in a Neubauer hemocytometer chamber after fixation with lugol using a light microscope. Aliquots of $T$. suecica cells were harvested by centrifugation $(1,500 \mathrm{~g}$ for $10 \mathrm{~min}$ at $15^{\circ} \mathrm{C}$ ) each day and stored at $-20^{\circ} \mathrm{C}$ until the analysis.

\section{Characterization and quantification of cadmium-induced thiols}

Thiol peptides were extracted from frozen samples and derivatized with monobromobimane that specifically labels sulfhydryl-containing compounds. Separation and analysis of labeled-thiol peptides were carried out using capillary electrophoresis [18]. The equipment used was a HP3DCE (Capillary Electrophoresis System; Agilent Technologies, Waldbronn, Germany). Standards of phytochelatins, cysteine, $\gamma$-Glu-Cys, and GSH, derivatized in the same way as the biological samples, were used to identify the different peaks. Glutathione was used as a suitable calibrating substance for quantifying the different peaks.

\section{Determination of intracellular cadmium}

A 25-ml aliquot from each microalgal culture was centrifuged at $1,500 \mathrm{~g}$ for 5 min, and the pellet was resuspended for $20 \mathrm{~min}$ in $25 \mathrm{ml}$ of a solution containing $0.02 \mathrm{M}$ EDTA dissolved in seawater. Afterward, the cells were centrifuged (1,500 g for $10 \mathrm{~min}$ 
at $15^{\circ} \mathrm{C}$ ) and washed twice with seawater. The cellular pellet was digested for $24 \mathrm{~h}$ with $1 \mathrm{ml}$ of $15 \mathrm{M} \mathrm{HNO} 3$ and $0.5 \mathrm{ml} \mathrm{HClO} 4$. The cadmium in the samples was measured by inductively coupled plasma-mass spectrometry (ICP-MS) using a VG Elemental Plasma Quad 2 ICP-MS System (VG Elemental, Offenbach, Germany) [20].

\section{Stability of phytochelatins and their precursors after transferring to metal- free medium}

Tetraselmis suecica cells exposed to a cadmium concentration of $7.9 \mathrm{mg} / \mathrm{L}$ for $7 \mathrm{~d}$ were transferred to metal-free medium to monitor the persistence of phytochelatins and their precursors in cells. Cultures were carried out as described above.

Cells were harvested by centrifugation $\left(1,500 \mathrm{~g}\right.$ for $10 \mathrm{~min}$ at $\left.15^{\circ} \mathrm{C}\right)$ and resuspended in a solution containing 0.02 M EDTA dissolved in seawater. Cells were kept in this solution for $10 \mathrm{~min}$; afterward, cells were centrifuged (1,500 g for $10 \mathrm{~min}$ at $15^{\circ} \mathrm{C}$ ) and washed twice with seawater. Washing with EDTA removed the cadmium adsorbed onto the cell surface. Cells were resuspended in metal-free seawater enriched with inorganic nutrients without EDTA and TRIS. Cultures were carried out as described above. Thiols and the intracellular concentration of the metal were monitored during the assay (as indicated above) every $2 \mathrm{~h}$ during the phase of light for a short time course evaluation $(10 \mathrm{~h})$.

\section{Statistical analysis}

Data were analyzed using the statistical program SPSS 11.5 (SPSS Iberica, Madrid, Spain). The results were tested by oneway analysis of variance (ANOVA), and the mean values of the various treatments were compared by Duncan's multiple-range test to a level of $5 \%$.

\section{RESULTS}

\section{Effect of cadmium on $T$. suecica growth}

Cultures of $T$. suecica exposed to different cadmium concentrations (3, 7.9, 15, and $30 \mathrm{mg} / \mathrm{L}$ ) showed significant differences in their growth. Growth inhibition was observed in all cultures exposed to cadmium with respect to the control culture without 
metal. The ANOVA test $(p>0.05)$ showed that this inhibitory effect on growth was significant in all cultures. The inhibition was proportional to cadmium concentration: As cadmium concentration increased in the medium, growth decreased (Fig. 1). A stimulating effect (hormesis) was observed during the first $4 \mathrm{~d}$ in cultures exposed to the lower cadmium concentration $(3 \mathrm{mg} / \mathrm{L})$, but later, the growth decreased significantly. Growth was not observed in cultures containing the highest cadmium concentration (30 $\mathrm{mg} / \mathrm{L})$.

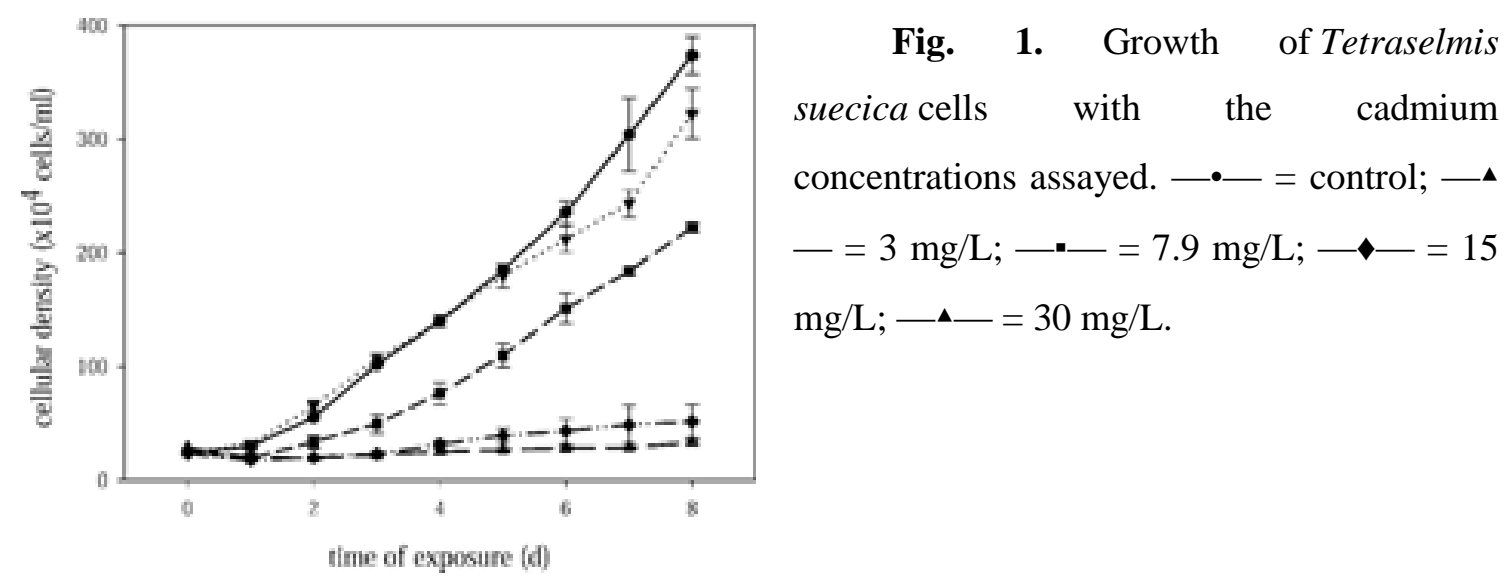

Characterization and quantification of thiols in $\mathbf{T}$. suecica cells by a capillary zone electrophoresis technique

A capillary zone electrophoresis technique was used to measure GSH, $\gamma$-Glu-Cys, the amino acid cysteine, and phytochelatins previously derivatized with monobromobimane [18]. Desglycyl-peptides also were detected. Using this technique, all the thiols mentioned previously could be analyzed in the same run.

\section{GSH, $\gamma$-Glu-Cys, and cysteine}

The synthesis of these low-molecular-weight thiols depends on the concentration of cadmium added to the medium (Fig. 2).

Tetraselmis suecica cells treated with the lowest cadmium concentration ( $3 \mathrm{mg} / \mathrm{L})$ showed decreased GSH content during the first day of exposure. Later, GSH increased until it reached the initial content and then remained steady without significant differences $(p<0.05)$ until day 6 , increasing slightly at the end of the culture period. However, GSH content never exceeded the amount synthesized by the control or the amount presented on day 0 , with $202.48 \pm 41.87$ amol $-\mathrm{SH} /$ cell (where a $=10^{-18} \mathrm{~mol}$ 
and -SH refers to thiol group) being the highest GSH content (the last day of culture) detected in cultures with $3 \mathrm{mg} / \mathrm{L}$ of cadmium. The $\gamma$-Glu-Cys did not show significant differences along the assay in cells exposed to this low cadmium concentration (3 $\mathrm{mg} / \mathrm{L}$ ), with $121.14 \pm 61.72 \mathrm{amol}-\mathrm{SH} /$ cell being the highest amount measured, detected on the fourth day of culture. Nevertheless, cysteine showed an increase higher than that of GSH and $\gamma$-Glu-Cys, reaching a value of $316.38 \pm 17.395 \mathrm{amol}-\mathrm{SH} / \mathrm{cell}$ on the seventh day of culture.

Cultures containing $7.9 \mathrm{mg} / \mathrm{L}$ of cadmium showed decreased amounts of GSH and $\gamma$-Glu-Cys on the first day; after $2 \mathrm{~d}$, the concentration of these peptides remained without significant changes $(p<0.05)$ until the last day of culture, when the amount of GSH increased slightly and reached $240.98 \pm 18.56 \mathrm{amol}-\mathrm{SH} /$ cell. The concentration of GSH did not exhibit significant differences among control cultures and those exposed to 3 and $7.9 \mathrm{mg} / \mathrm{L}$ of cadmium (Fig. $2 \mathrm{a}-\mathrm{c}$ ).

The highest GSH levels were obtained in cultures treated with $15 \mathrm{mg} / \mathrm{L}$ of cadmium, exceeding the levels observed on day 0 from the second day of treatment and reaching the highest amounts of GSH of the four cadmium concentrations assayed. The highest concentration of this small peptide was reached on the sixth day of culture $(633.06 \pm 238.82 \mathrm{amol}-\mathrm{SH} / \mathrm{cell})$, being 3.3-fold higher than the levels observed on day 0 and 2.9-fold higher with respect to the control on the same day of culture (Fig. 2d).

The concentration of GSH in cultures exposed to $30 \mathrm{mg} / \mathrm{L}$ of cadmium decreased on the first day, but during later days, the levels of this peptide increased substantially with respect to cultures treated with the lower cadmium concentrations, decreasing only on the last day (Fig.2e). The highest amount was reached after $7 \mathrm{~d}$ of culture, being 3.1fold higher than that on day 0 and 2.8-fold higher with respect to the control. Therefore, the levels of GSH in cells treated with 15 and $30 \mathrm{mg} / \mathrm{L}$ of cadmium exceeded substantially the amount measured in control cultures.

The amino acid cysteine, however, exceeded in all cultures the concentrations reached in controls. The amount reached by this amino acid was higher at the higher cadmium concentrations (Fig. 2). 

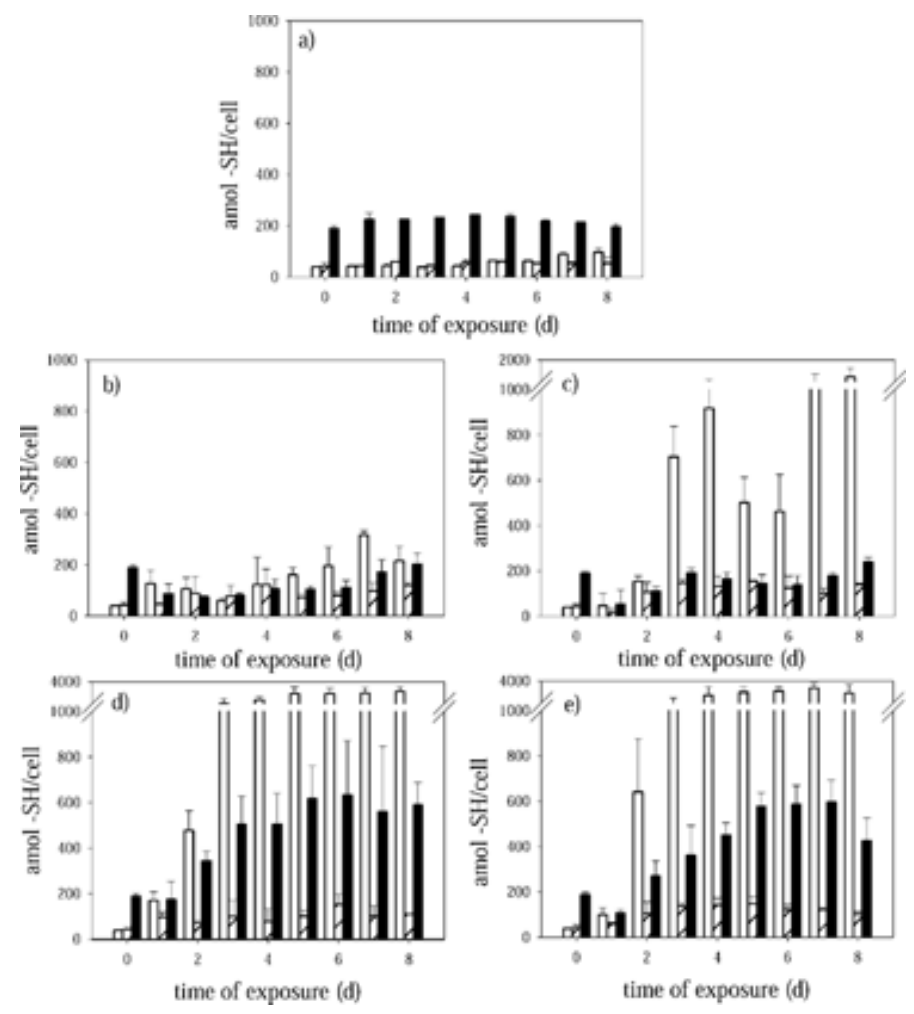

Fig. 2. Time course of glutathione (GSH), $\gamma$-glutamylcysteine $(\gamma$-EC), and the amino acid cysteine concentration in cells of Tetraselmis suecica in response to different cadmium concentrations expressed as amol $-\mathrm{SH} /$ cell (where $\mathrm{a}=$ $10^{-18} \mathrm{~mol}$ and $-\mathrm{SH}$ refers to thiol group). (a) Control; (b) $3 \mathrm{mg} / \mathrm{L}$; (c) $7.9 \mathrm{mg} / \mathrm{L}$; (d) $15 \mathrm{mg} / \mathrm{L}$; and (e) 30 $\mathrm{mg} / \mathrm{L}$. Data bars represent the means of three sample replicates \pm standard deviation.

The concentrations of the amino acid cysteine increased from the first day of culture in all the concentrations assayed. This amino acid increased substantially in cells exposed to 15 and $30 \mathrm{mg} / \mathrm{L}$ of cadmium and exceeded by 74.7- and 86.1-fold the amount recorded on day 0 , reaching a concentration of 2,915.02 \pm 487.12 and 3,359.54 \pm 499.15 amol $-\mathrm{SH} /$ cell, respectively (Fig. $2 \mathrm{~d}$ and e). The amino acid cysteine also increased significantly in cultures treated with $7.9 \mathrm{mg} / \mathrm{L}$ of cadmium after the second day, reaching an amount on the last day that was 35.1-fold higher than that on day 0 . Cysteine began to increase on the fourth day of culture in cells treated with $3 \mathrm{mg} / \mathrm{L}$ of cadmium. Cysteine reached a concentration that was 30.1- and 38.2-fold higher than that of the control in cultures containing 15 and $30 \mathrm{mg} / \mathrm{L}$ of cadmium, respectively, on the days ( 8 and 7 , respectively) in which this amino acid reached the highest values. This amino acid exhibited significant differences compared with $\gamma$-Glu-Cys and GSH in cultures with 7.9, 15, and $30 \mathrm{mg} / \mathrm{L}$ of cadmium $(p>0.05)$.

The dipeptide $\gamma$-Glu-Cys presented the fewest changes at the cadmium concentrations tested. After the second day, in the cultures containing 3 and $7.9 \mathrm{mg} / \mathrm{L}$ of cadmium, this peptide remained without significant differences $(p<0.05)$, with the highest concentration of $\gamma$-Glu-Cys measured being in cultures treated with $7.9 \mathrm{mg} / \mathrm{L}$ of cadmium when a concentration of $152.63 \pm 45.01 \mathrm{amol}-\mathrm{SH} /$ cell was reached. In the 
same way, in cultures exposed to 15 and $30 \mathrm{mg} / \mathrm{L}$ of cadmium, this small peptide remained without major variations.

\section{Phytochelatins}

The time course analysis showed that the concentrations of phytochelatins and their number of subunits depend on the amount of cadmium added to the culture and on the time of exposure (Fig. 3). Synthesis of phytochelatins was not detected with the technique applied in the control and at day 0 of each culture.

Synthesis of phytochelatins showed a similar pattern in cultures with 3 and 7.9 $\mathrm{mg} / \mathrm{L}$ of cadmium (Fig. 3a and b). The levels of the different types of phytochelatins in cultures treated with 3 and $7.9 \mathrm{mg} / \mathrm{L}$ of cadmium increased progressively in the course of time. The $(\gamma-\mathrm{EC})_{2} \mathrm{G}$ to $(\gamma-\mathrm{EC})_{5} \mathrm{G}$ were detected under both assayed cadmium concentrations.

The rate of $(\gamma-E C)_{3} \mathrm{G}$ accumulation was higher than that of any other type of phytochelatins in cells exposed to the lowest cadmium concentration studied ( $3 \mathrm{mg} / \mathrm{L})$ for all days of culture, reaching a value of 3,859.60 $\pm 553.11 \mathrm{amol}-\mathrm{SH} / \mathrm{cell}$. However, in cultures treated with $7.9 \mathrm{mg} / \mathrm{L}$ of cadmium, $(\gamma-\mathrm{EC})_{4} \mathrm{G}$ increased substantially after $7 \mathrm{~d}$ of culture, exceeding the amount of $(\gamma-\mathrm{EC})_{3} \mathrm{G}$ and reaching a concentration of 4,540.19 $\pm 1,042.13 \mathrm{amol}-\mathrm{SH} / \mathrm{cell}$. The peptide $(\gamma \text {-EC })_{4} \mathrm{G}$ exceeded by 17 -fold the initial amount of this type of phytochelatin. A $(\gamma-\mathrm{EC})_{6} \mathrm{G}$ was detected from the fifth day of culture in cells exposed to $7.9 \mathrm{mg} / \mathrm{L}$ of cadmium, and a $(\gamma-\mathrm{EC})_{7} \mathrm{G}$ appeared on the last day of culture in this same cadmium concentration.

Phytochelatins of cultures exposed to $15 \mathrm{mg} / \mathrm{L}$ of cadmium increased until the fourth day of culture, with the amount of $(\gamma-\mathrm{EC})_{3} \mathrm{G}$ being significantly higher than that of the other types of phytochelatins ( $p>0.05$ ), reaching a concentration of 3,299.87 \pm 438.17 amol -SH/cell (Fig.3c). After a 4-d culture, phytochelatin levels decreased gradually, coincident with a considerable increase in GSH and cysteine (Fig. 2d).

As in cultures exposed to $15 \mathrm{mg} / \mathrm{L}$ of cadmium, cells of $T$. suecica treated with the highest cadmium concentration $(30 \mathrm{mg} / \mathrm{L})$ showed a decrease in the concentration of phytochelatins after $3 \mathrm{~d}$ of culture (Fig. 3d). At the same time, an increase in the concentration of cysteine and GSH was measured. The amount of $(\gamma-E C)_{3} \mathrm{G}$, as in cultures exposed to 3 and $15 \mathrm{mg} / \mathrm{L}$ of cadmium, was significantly higher than that of the 
other types of phytochelatins $(p>0.05)$, reaching a concentration of $3,123.71 \pm$ $1,210.354 \mathrm{amol}-\mathrm{SH} / \mathrm{cell}$.
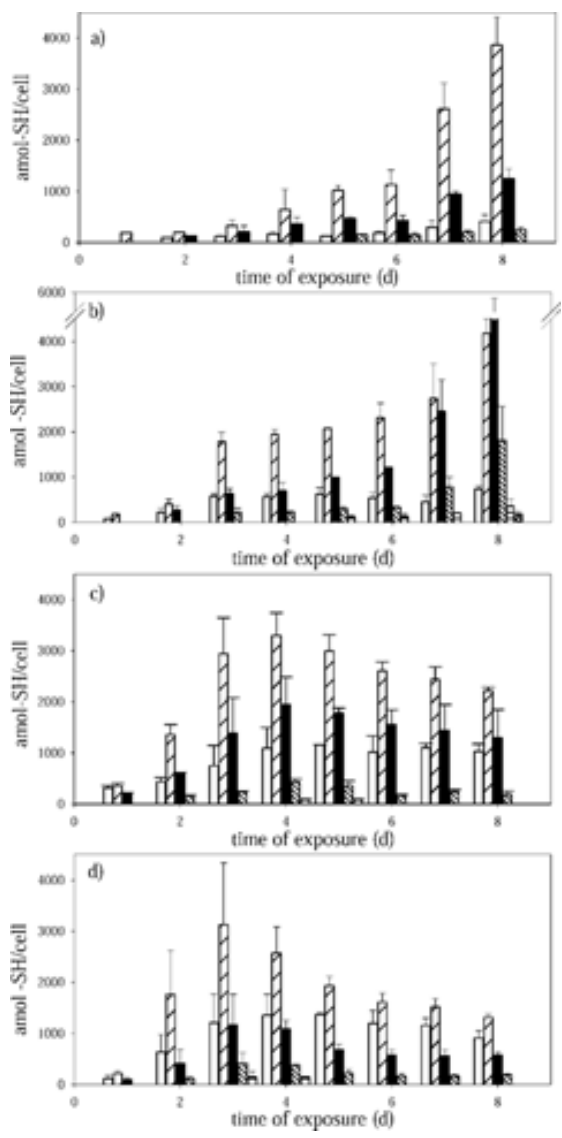

Fig. 3. Time course of phytochelatin $(\gamma-$ $(\mathrm{EC}) n \mathrm{G})$ synthesis in Tetraselmis suecica exposed to different cadmium concentrations expressed as amol $-\mathrm{SH} /$ cell (where $\mathrm{a}=10^{-18} \mathrm{~mol}$ and $-\mathrm{SH}$ refers to thiol group). (a) $3 \mathrm{mg} / \mathrm{L}$; (b) $7.9 \mathrm{mg} / \mathrm{L}$; (c) 15 $\mathrm{mg} / \mathrm{L}$; and (d) $30 \mathrm{mg} / \mathrm{L}$. Data bars represent the means of three sample replicates \pm standard

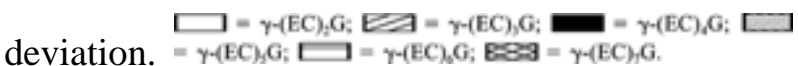

\section{Desglycyl-phytochelatins}

The capillary zone electrophoresis technique used for the quantification and characterization of the different thiol compounds allowed the identification and separation of desglycyl-phytochelatins [18].

These types of peptides were not detected during the two first days of culture in the cells exposed to 3 and $7.9 \mathrm{mg} / \mathrm{L}$ of cadmium, although in cultures exposed to 30 $\mathrm{mg} / \mathrm{L}$ of cadmium, these peptides were already detected on the second day (and from the first day in the cultures treated with $15 \mathrm{mg} / \mathrm{L}$ of cadmium) (Fig. 4). 

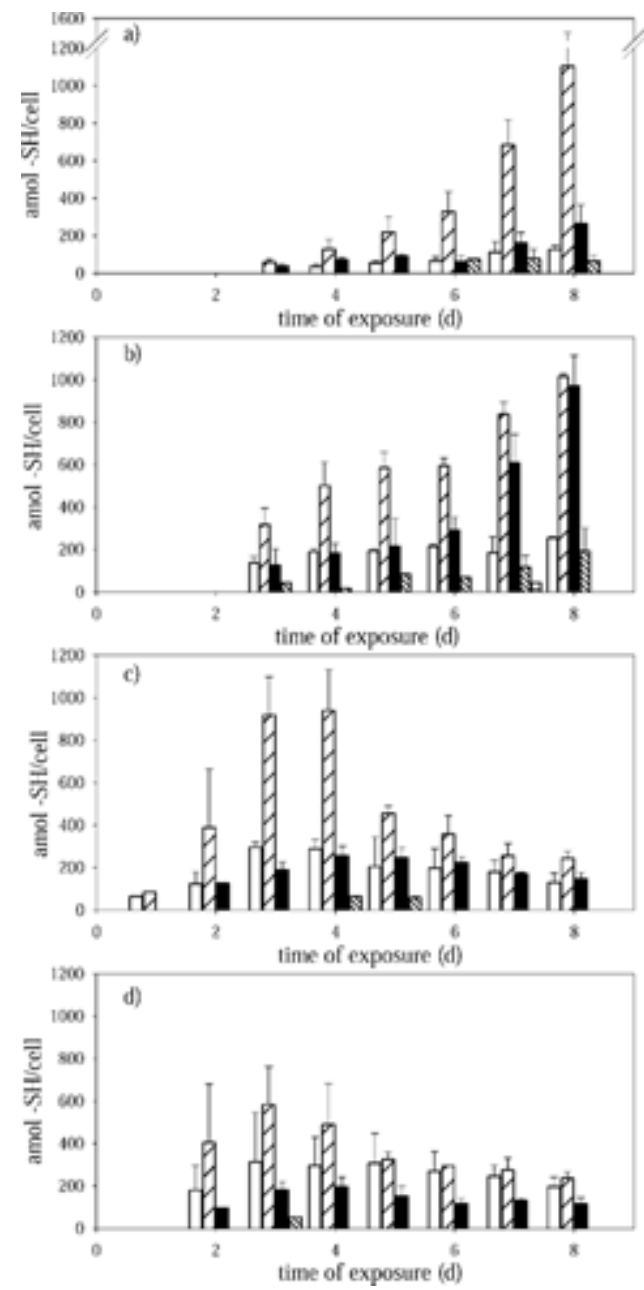

Fig. 4. Time evolution of desglycylphytochelatins $\quad(\gamma-(\mathrm{EC}) n) \quad$ in $\quad$ cultures of Tetraselmis suecica exposed to different cadmium concentrations expressed as amol $\mathrm{SH} /$ cell (where $\mathrm{a}=10^{-18} \mathrm{~mol}$ and $-\mathrm{SH}$ refers to thiol group). (a) $3 \mathrm{mg} / \mathrm{L}$; (b) $7.9 \mathrm{mg} / \mathrm{L}$; (c) $15 \mathrm{mg} / \mathrm{L}$; and (d) $30 \mathrm{mg} / \mathrm{L}$. Data bars represent the means of three sample replicates \pm standard deviation.

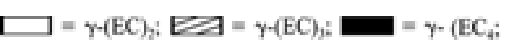

$\square=\gamma(\mathrm{EC}) ; \square=\gamma(\mathrm{EC})$.

The time course of these desglycyl-peptides followed the same pattern as that of phytochelatins in the different cadmium concentrations. The concentration of desglycylphytochelatins in cultures treated with 3 and $7.9 \mathrm{mg} / \mathrm{L}$ of cadmium increased gradually during the assay. However, in the cultures exposed to 15 and $30 \mathrm{mg} / \mathrm{L}$ of cadmium, the different types of desglycyl-peptides decreased from the fourth and third day, respectively.

The concentration of $(\gamma \text {-EC })_{3}$ significantly exceeded $(p>0.05)$ that of the other types of desglycyl in all the concentrations of cadmium assayed, with 1,102.048 \pm $369.166,1,014.327 \pm 13.80,939.445 \pm 192.268$, and $582.931 \pm 179.351 \mathrm{amol}-\mathrm{SH} / \mathrm{cell}$ being the highest levels of $(\gamma \text {-EC })_{3}$ reached in the cultures treated with 3, 7.9, 15, and 30 $\mathrm{mg} / \mathrm{L}$ of cadmium, respectively. 

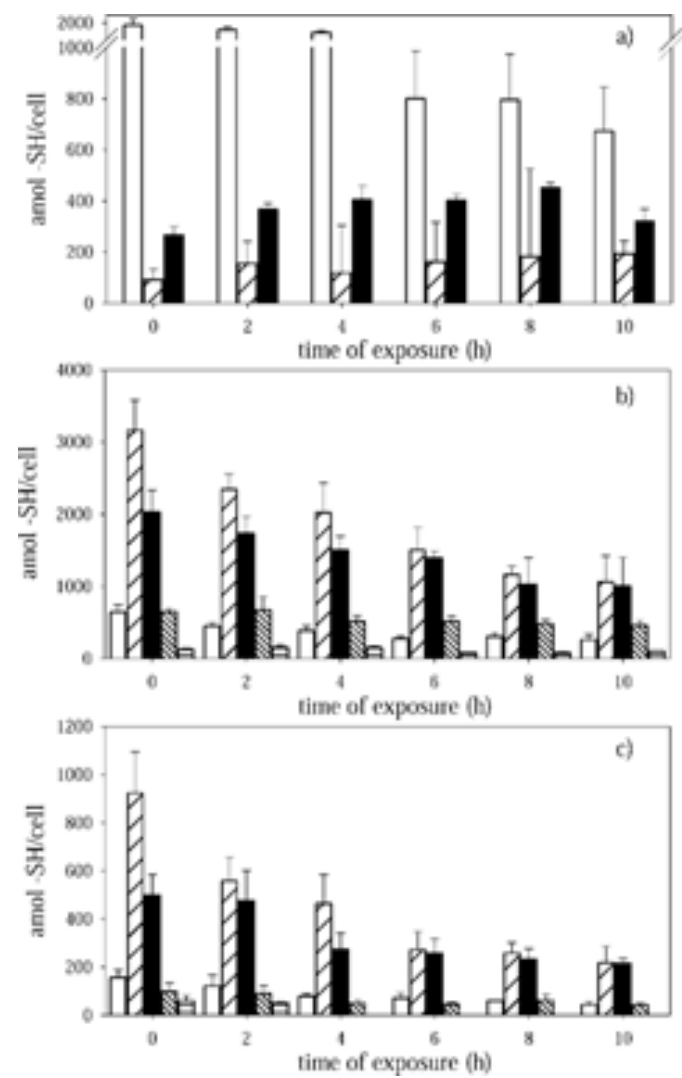

Fig. 5. Time evolution of thiol pools on resuspension of cells in medium without metal (cells were previously exposed to $7.9 \mathrm{mg} / \mathrm{L}$ of cadmium for $7 \mathrm{~d}$ ) expressed as amol -SH/cell (where $\mathrm{a}=10^{-18} \mathrm{~mol}$ and $-\mathrm{SH}$ refers to thiol group. (a) Time course of the amino acid cysteine and precursors of phytochelatins, glutathione (GSH), and $\gamma$-glutamylcysteine $(\gamma$ $\mathrm{EC})$.

GSH. (b) Time course of phytochelatins ( $\gamma-(\mathrm{EC}), \mathrm{G}) \mathrm{-EC}$ $(\mathrm{EC})_{2} \mathrm{G} ; \mathrm{E}=\gamma-(\mathrm{EC})_{3} \mathrm{G} ; \mathrm{C}=\gamma-(\mathrm{EC})_{4} \mathrm{G} ; \mathrm{L}=\gamma-(\mathrm{EC})_{3} \mathrm{G}$ $\mathrm{Z}=\gamma$ (EC),G. (e) Time course of desglycyl-phytochelatins $(\gamma-$ $=\gamma$-(EC)si $=\gamma$-(EC). Dats bars represent the means of three sample replicates \pm standard deviation.

\section{Stability of phytochelatins after transferring to a metal-free medium}

Cells of $T$. suecica exposed to $7.9 \mathrm{mg} / \mathrm{L}$ of cadmium for $7 \mathrm{~d}$ were transferred to metal-free medium. Phytochelatins, desglycyl-phytochelatins, GSH, $\gamma$-Glu-Cys, and cysteine were monitored for $10 \mathrm{~h}$. Phytochelatins, desglycyl-phytochelatins, and the amino acid cysteine decreased gradually with time (Fig. 5). This reduction mainly affected $(\gamma-\mathrm{EC})_{3} \mathrm{G}$ and $(\gamma-\mathrm{EC})_{4} \mathrm{G}$, with these being the most abundant type of phytochelatins at the beginning of the assay (Fig.5b). The decrease in desglycylpeptides also mainly affected $(\gamma \text {-EC })_{3}$ and $(\gamma \text {-EC })_{4}$. A decrease in the concentration of phytochelatins occurred simultaneously with a cellular increase in GSH and $\gamma$-Glu-Cys (Fig. 5a). These small peptides exceeded by 1.6- and 2.1-fold, respectively, the concentration at the beginning of the assay, although the concentration reached by $\gamma$ Glu-Cys was 2.6-fold lower than that of GSH.

The analysis of intracellular cadmium showed that the intracellular concentration of this metal was constant during the assay $(10 \mathrm{~h})$. 


\section{DISCUSSION}

Cadmium toxicity was clearly demonstrated; however, what generally is accepted to be deleterious to living organisms provoked a hormesis effect in cultures of the marine microalga T. suecica exposed to $3 \mathrm{mg} / \mathrm{L}$. Also, Lane and Morel [21] provided evidence of a biological role for cadmium in the marine diatom Thalassiosira weissflogii. The addition of cadmium to zinc-limited cultures increased the growth rate. Those authors found that this microalga expresses a cadmium-specific carbonic anhydrasa that could substitute the zinc enzyme TWCA1 (T. weissflogii carbonic anhydrase), the major intracellular carbonic anhydrasa.

Marine microalgae are among the organisms that tolerate higher concentrations of this metal. Tetraselmis suecica is a good example of a tolerant microalga. The EC50 value obtained for the growth of this species exposed to cadmium was $7.9 \mathrm{mg} / \mathrm{L}$ cadmium [20]. This value indicates that this mi-croalgal species is one of the most tolerant to this metal. One of the reasons for this tolerance is the ability of this species to synthesize phytochelatins and related molecules. Different reports have shown that biosynthesis of phytochelatins seems to be one of the main tolerance mechanisms to metals, with cadmium being one of the main inductors [22,23]. In fact, a previous analysis showed that approximately $87 \%$ of the bioaccumulated cadmium was bound by phytochelatins when this microalga was exposed to $6 \mathrm{mg} / \mathrm{L}$ of cadmium for $8 \mathrm{~d}$ [24]. The concentration of thiol groups in $T$. suecica also increased as cadmium increased in the medium, with this increase being higher with the higher cadmium concentrations assayed [20]. These results agree with the increase in phytochelatins in the cultures treated with 3 and $7.9 \mathrm{mg} / \mathrm{L}$ of cadmium. The synthesis of phytochelatins allows a great capacity to bind cadmium that prevents the metal from affecting the cellular targets. Ahner et al. [25] exposed eight species of eukaryotic microalgae to increased concentrations of cadmium. Those algae exhibited a similar response, and those authors observed that the concentration of phytochelatins increased with that of cadmium. This fact is common to the species of phytoplankton investigated; therefore, it could be considered to be a general response.

The present results, however, showed that phytochelatin synthesis is an effective defense mechanism in the response to cadmium, but only at metal concentrations less than the EC50. Cultures of $T$. suecica exposed to the higher cadmium concentrations 
(15 and $30 \mathrm{mg} / \mathrm{L}$ ) showed a decrease in the levels of phytochelatins after 4 and $3 \mathrm{~d}$ of exposure, respectively; nevertheless, the number of thiol groups did not decrease [20]. Although growth was totally inhibited in cultures exposed to the higher cadmium concentrations, synthesis of the amino acid cysteine was high (and synthesis of GSH was less), reaching a concentration 86.1-fold higher than that on day 0 on the seventh day of culture. In the same way, cells treated with $15 \mathrm{mg} / \mathrm{L}$ of cadmium showed a substantial increase in cysteine (74.7-fold higher than on day 0), although growth was near zero. At these high cadmium concentrations, this amino acid might be acting as main chelator for cadmium. Previously, intracellular cadmium in cells of $T$. suecica exposed to $30 \mathrm{mg} / \mathrm{L}$ was shown to exceed considerably the amount of intracellular cadmium existing in the cultures with lower concentrations from the first day [20]; therefore, cadmium was bioaccumulated in this culture. Bearing this in mind, the present study demonstrated that cysteine might be the principal chelator of cadmium when the concentration of this metal is so high that synthesis of phytochelatins is restricted. The role of cysteine in metal detoxification was studied in several microalgae and plants. Exposure to cobalt ions resulted in increased citrate and cysteine levels in cells of Crotalaria cobalticola, where the synthesis of phytochelatins was not induced [12]. The synthesis of cysteine in a tolerant strain of Scenedesmus acutus increased with the cadmium concentration assayed, reaching an amount that was fivefold higher than that of the wild strain in the culture with the higher cadmium concentration $(27 \mu \mathrm{M})$; a decrease in phytochelatins also was observed both in the tolerant and the wild strains when cadmium concentrations were increased [26]. Ahner et al. [14] reported that cysteine increased with cadmium concentration and exceeded the concentration of GSH at the highest cadmium concentrations in the different species of microalgae assayed. Transgenic plants of Arabidopsis with altered GSH levels were unable to synthesize phytochelatins; however, in these plants, the steady state of cysteine concentration increased twofold in response to cadmium exposure [27]. Consequently, as the concentration of cadmium overcomes a specific value (possibly the EC50 for growth of the species), the toxic effect of cadmium blocks the synthesis of phytochelatins, with cysteine being the main chelating agent. However, cysteine presents a lower capability of chelating the metal; therefore, cysteine would not avoid cadmium toxicity when a high intracellular concentration of this metal exists. Therefore, in cultures exposed to 15 and $30 \mathrm{mg} / \mathrm{L}$ of cadmium, growth inhibition is not prevented. 
The data indicate that the halt in the synthesis of phytochelatins in cultures containing the higher cadmium concentration result from an inhibition in phytochelatin synthase, because the synthesis of cysteine and GSH continued and the concentration of these two molecules increased. One explanation for this result is deduced from the catalytic characteristics of phytochelatin synthase [28]. This enzyme requires free GSH for the catalysis. In cultures with higher concentrations of cadmium, the union of this metal blocks all available GSH. This indicates an increase in GSH synthesis (Fig. 2d and e) to compensate for the one that is blocked, but this synthesis is insufficient to generate free GSH. Therefore, no synthesis of phytochelatins occurs. These processes provoke that the cadmium remains free and causes the toxicity.

It is necessary to emphasize that in contrast to what happens with the synthesis of phytochelatins, the synthesis of cysteine is very high in cultures with a high cadmium concentration, indicating that the enzymes involved in the synthesis of this molecule are very active. For example, in plants of Arabidopsis thaliana exposed to cadmium, expression of the cytosolic $O$-acetyl-serine(thiol)lyase gene is high [13]. Therefore, in the cells of $T$. suecica, despite being exposed to high cadmium concentrations, the metabolism of sulfur (assimilation pathway) continues to be high. Under these conditions, cysteine becomes the mayor thiol in the cells.

Glutathione levels in cultures exposed to cadmium concentrations less than the EC50, however, recuperated as the culture progressed, reaching values similar to (or only slightly higher than) those of the control. From this, it is deduced that the capacity of GSH synthesis is sufficient to compensate for its loss because of the synthesis of phytochelatins and the one that has been blocked by cadmium complexation. This maintains the GSH levels that are needed for other functions, allowing these cultures to continue growing, although with a lower growth rate than that of the control (Fig. 1).

Tetraselmis suecica also showed decreased GSH on the first day of culture with respect to that on day 0 in all cultures exposed to cadmium. This same pattern was observed in most algae and in plants [23]. In fact, in plant cells, a general tendency is a concomitant disappearance of GSH and the appearance of phytochelatins [29]. This general response is explained by the demands of GSH for synthesis of phytochelatins. Also, cadmium provokes the production of reactive oxygen species that induce the 
activity of antioxidant enzymes, such as superoxide dismutase, or low-molecular-weight antioxidants, such as GSH [30].

It is interesting that the level of $\gamma$-Glu-Cys remained without significant increases in all cultures, even those with the highest cadmium concentration, in which both GSH and cysteine presented a strong increase. This seems to indicate that the activity of $\gamma$ Glu-Cys synthetase did not increase greatly because of cadmium in $T$. suecica cells; therefore, $\gamma$-Glu-Cys levels remained constant in all cultures. This same effect was observed in plants of Brassica juncea, in which the transcript amount for $\gamma$-Glu-Cys synthetase did not change significantly after cadmium exposure [31]. Although cadmium did not induce higher expression of the gene for this enzyme, its activity possibly was increased by the action of the metal; nevertheless, our results seem to indicate that this did not occur. These results confirm, as generally accepted, that $\gamma$-GluCys synthetase is the rate-limiting step in GSH biosynthesis $[\mathbf{3 2 , 3 3}]$ and, therefore, in the synthesis of phytochelatins, because as observed in the obtained data, cysteine synthesis does not rate-limit GSH production under the conditions of toxicity for cadmium. Elevated $\gamma$-Glu-Cys synthetase activity (i.e., overexpression) was shown to correlate with cadmium resistance in cultured tomato cells [34] and in B. juncea [35].

According to the present results, a model for the interaction of cadmium with the enzymes involved in the biosynthetic pathway of phytochelatins in the microalga $T$. suecica is presented in Figure 6.

Phytochelatins and cysteine are important cellular components involved in mechanisms of tolerance to cadmium, with the intracellular level of these molecules being regulated by the concentration of this metal in the medium. The size of the phytochelatins, however, also is an important aspect for the reduction of cadmium toxicity. The ability of an organism to synthesize phytochelatins with a greater number of subunits would allow it to tolerate a higher concentration of cadmium; therefore, it would increase the EC50. In the case of T. suecica, phytochelatins with up to seven subunits were detected. The most abundant phytochelatin had four subunits (Fig. 3b). These phytochelatins are produced in cultures with the cadmium concentration that implies the EC50 for the growth of this species. The elevation of this metal concentration exceeds the homeostatic characteristics of $T$. suecica(reduction in the synthesis of phytochelatins is produced), and growth is inhibited. 
A second family of thiol peptides was characterized in $T$. suecica, the desglycylphytochelatins with the general structure $(\gamma$-Glu-Cys $) n$. The desglycyl-phytochelatins were described previously in yeast [36] and in plants [9,37]. Meuwly et al. [37] described three families of thiol peptides in maize treated with cadmium: ( $\gamma$-Glu-Cys) $n$, ( $\gamma$-Glu-Cys)n-Gly, and ( $\gamma$-Glu-Cys)n-Glu [37]. Also, Rubia tinctorum exposed to different metals synthesized ( $\gamma$-Glu-Cys) $n$-Gly and ( $\gamma$-Glu-Cys) $n$ [38]. Desglycylphytochelatins appeared on exposure to metals; therefore, as phytochelatins, they could act in the detoxification of metals. However, desglycyl-peptides and phytochelatins showed a similar pattern of synthesis in T. suecica (Figs. 3 and 4), with the desglycyl peptides concentration being substantially lower than that of phytochelatins. Today, doubts exist about the biosynthetic origin of these molecules. One possible origin might be a process of degradation of phytochelatins because of the action of a carboxypeptidase [7]. Nevertheless, the data obtained in the present work indicate a pattern of synthesis correlated with that of the phytochelatins, which might indicate that the desglycyl-phytochelatins would be a residual activity of phytochelatin synthase, which also might polymerize subunits of $\gamma$-Glu-Cys. When the activity of this enzyme decreased in cultures exposed to 15 and $30 \mathrm{mg} / \mathrm{L}$ of cadmium, decreasing the amount of phytochelatins, the amount of desglycyl-phytochelatins also decreased in the same way.

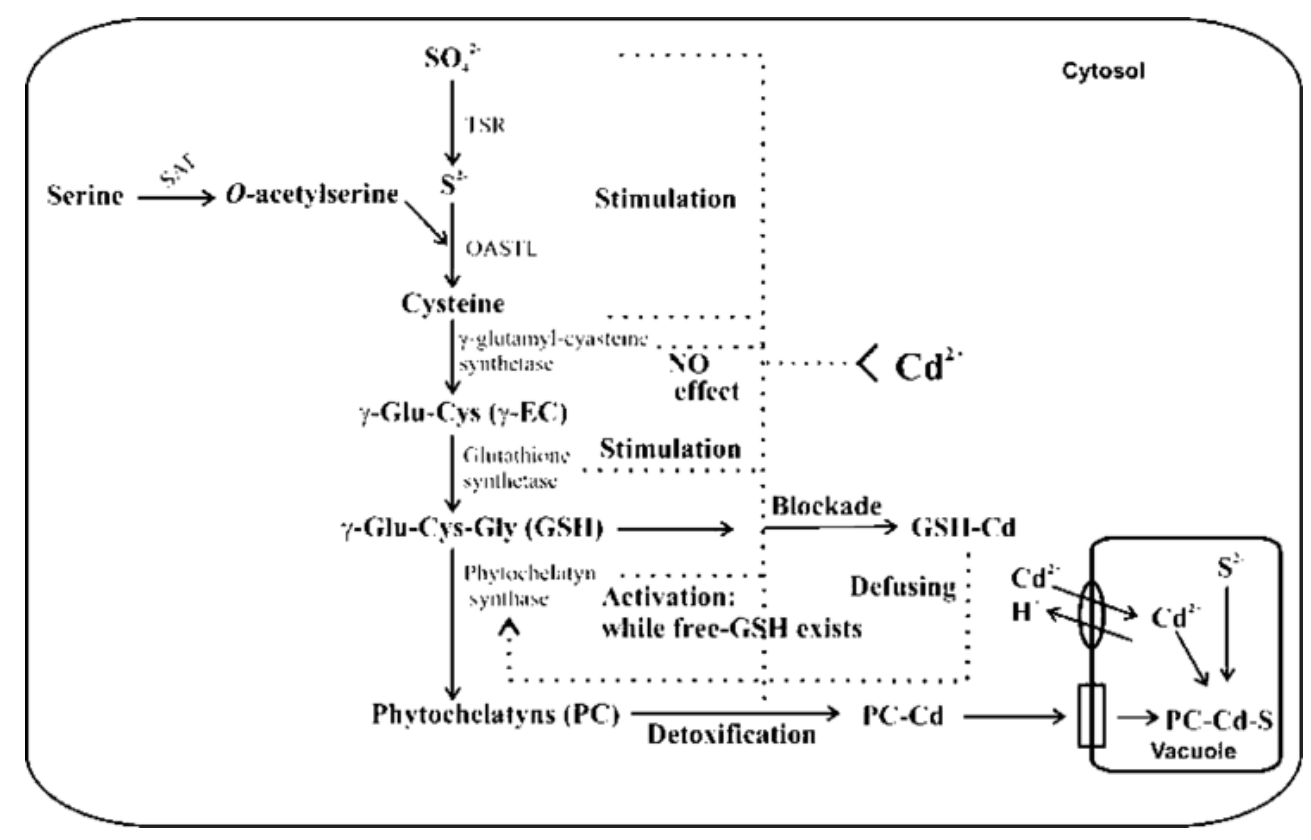

Figure Fig. 6. Schematic representation of cadmium interaction with the different enzymes involved in the biosynthetic pathway of phytochelatins. For a detailed explication, see 
the text. $\gamma$-EC $=\gamma$-glutamylcysteine; GSH $=\gamma$-glutamylcysteine-Gly; OASTL $=O$-acetylserine thiol lyase; $\mathrm{PC}=$ phytochelatins; $\mathrm{SAT}=$ serine acetyl transferase; $\mathrm{TSR}=$ thiosulfate reductase .

In cultures that were placed in a medium without cadmium, rapid loss of phytochelatins from the cells occurs after exposure to an EC50 concentration of this metal. After $10 \mathrm{~h}$, the content of phytochelatins diminished to $50 \%$ of the initial concentration (Fig. 5). The quantity of cysteine also diminished, but the quantities of GSH and $\gamma$-Glu-Cys increased. Loss of phytochelatins also occurred in $T$. weissflogii and Phaeodactylum tricornutum previously exposed to cadmium and lead, respectively $[39,40]$. The decrease in levels of phytochelatins indicates an excretion or degradation process; in fact, in both plants and yeast, phytochelatin-cadmium complexes are sequestered into vacuoles. However, no excretion of metals was observed in $T$. suecica during the assay $(10 \mathrm{~h})$. These data seem to indicate a degradation process of phytochelatins, with the metal remaining inside the vacuoles. Once the metal is excreted to the vacuoles, the phytochelatins would be degraded, decreasing their levels, because the activity of phytochelatin synthase also would be lower.

\section{Acknowledgements}

The present work was funded by the Plan Nacional de I + D (REN 2003-02414), Spain.

\section{References}

1. Rijstenbil JW, Sandee A, van Drie J, Wijnholds JA. 1994. Interaction of toxic trace metals and mechanisms of detoxification in the planktonic diatoms Ditylum brightwellii and Thalassiosira pseudonana. FEMS Microbiol Rev 14: 387-396.

2. Rijstenbil JW, Gerringa LJ. 2002. Interactions of algal ligands, metal complexation and availability, and cell responses of the diatom Ditylum brightwellii with a gradual increase in copper. Aquat Toxicol 56:115-131.

3. Tsuji N, Hirayanagi N, Iwabe O, Namba T, Tagawa M, Miyamoto S, Miyasaka H, Takagi M, Hirata K,Miyamoto K. 2003. Regulation of phytochelatin synthesis by zinc and cadmium in marine green alga,Dunaliella tertiolecta. Phytochemistry 62: 453-459. 
4. Rauser WE. 1995. Phytochelatins and related peptides. Structure, biosynthesis, and function. Plant Physiol 109: 1141-1149.

5. Torres E, Cid A, Fidalgo P, Herrero C, Abalde J. 1997. Long-chain class III metallothioneins as a mechanism of cadmium tolerance in the marine diatom Phaeodactylum tricornutum Bohlin. Aquat Toxicol 39: 231-246.

6. Meuwly P, Thibault P, Rauser WE. 1993. $\gamma$-Glutamylcysteinyl-glutamic acid-A new homologue of glutathione in maize seedlings exposed to cadmium. FEBS Lett 336: 472476.

7. Klapheck S, Fliegner W, Zimmer I. 1994. Hydroxymethyl-phytochelatins ( $\gamma$ glutamylcysteine) $n$-serine are metal-induced peptides of the Poaceae. Plant Physiol 104: 1325-1332.

8. Gupta DK, Tohoyama H, Joho M, Inouhe M. 2004. Changes in the levels of phytochelatins and related metal-binding peptides in chickpea seedlings exposed to arsenic and different heavy metal ions. J Plant Res 117: 253-256.

9. Maitani T, Kubota H, Sato K, Yamada T. 1996. The composition of metals bound to class III metallothionein (phytochelatin and its desglycyl peptide) induced by various metals in root cultures of Rubia tinctorum. Plant Physiol 110: 1145-1150.

10. Grill E, Löffler S, Winnacker E-L, Zenk MH. 1989. Phytochelatins, the heavy-metalbinding peptides of plants, are synthesized from glutathione by a specific $\gamma$ glutamylcysteine dipeptidyl transpeptidase (phytochelatin synthase). Proc Natl Acad Sci USA 86: 6838-6842.

11. Tsuji N, Nishikori S, Iwabe O, Shiraki K, Miyasaka H, Takagi M, Hirata K, Miyamoto K. 2004.Characterization of phytochelatin synthase-like protein encoded by alr0975 from a prokaryote, Nostoc sp. PCC 7120. Biochem Biophys Res Commun 315: 751-755.

12. Oven M, Grill E, Golan-Goldhirsh A, Kutchan TM, Zenk MH. 2002. Increase of free cysteine and citric acid in plant cells exposed to cobalt ions. Phytochemistry 60: 467-474.

13. Dominguez-Solis JR, Gutierrez-Alcala G, Vega JM, Romero LC, Gotor C. 2001. The cytosolic $O$-acetylserine(thiol)lyase gene is regulated by heavy metals and can function in cadmium tolerance. J Biol Chem 276: 9297-9302.

14. Ahner BA, Wei L, Oleson JR, Nori O. 2002. Glutathione and other low-molecular-weight thiols in marine phytoplankton under metal stress. Mar Ecol Prog Ser 232: 93-103.

15. Nassiri Y, Mansot JL, Wéry J, Ginsburger-Voge T, Amiard JC. 1997. Ultrastructural and electron energy loss spectroscopy studies of sequestration mechanism of $\mathrm{Cd}$ and $\mathrm{Cu}$ in the marine diatom Skletonema costatum. Arch Environ Contam Toxicol 33: 147-155.

16. Nassiri Y, Wéry J, Mansot JL, Ginsburger-Vogel T. 1997. Cadmium bioaccumulation in Tetraselmis suecica: An electron energy loss spectroscopy (EELS) study. Arch Environ Contam Toxicol 33: 156-191.

17. Yin L, Zhou Y, Fan X, Lu R. 2002. Induction of phytochelatins in Lemna aequinoctialis in response to cadmium exposure. Bull Environ Contam Toxicol 68: 561568.

18. Pérez-Rama M, Torres E, Abalde J. 2005. Capillary zone electrophoresis for analysis of phytochelatins and other thiol peptides in complex biological samples derivatized with monobromobimane.Electrophoresis 26: 610-620. 
19. Fabregas J, Abalde J, Herrero C, Cabezas B, Veiga M. 1984. Growth of the marine microalga Tetraselmis suecica in batch cultures with different salinities and nutrient concentrations. Aquaculture 42: 207-215.

20. Pérez-Rama M, Abalde J, Herrero C, Torres E. 2002. Cadmium removal by living cells of the marine microalga Tetraselmis suecica. Bioresour Technol 8: 265-270.

21. Lane TW, Morel FMM. 2000. A biological function for cadmium in marine diatoms. Proc Natl Acad Sci USA97: 4627-4631.

22. Scarano G, Morelli E. 2002. Characterization of cadmium- and lead-phytochelatin complexes formed in a marine microalga in response to metal exposure. Biometals 15: 145-151.

23. $\mathrm{Hu}$ SX, Lau KWK, Wu M. 2001. Cadmium sequestration in Chlamydomonas reinhardtii. Plant Sci (Limerick)161: 987-996.

24. Pérez-Rama M, Herrero C, Abalde J, Torres E. 2001. Class III metallothioneins in response to cadmium toxicity in the marine microalga Tetraselmis suecica (Kylin) Butch. Environ Toxicol Chem 20: 2061-2066.

25. Ahner BA, Kong S, Morel FMM. 1995. Phytochelatin production in marine algae. 1. An interspecies comparison. Limnol Oceanogr 40: 649-657.

26. Torricelli E, Gorbi G, Pawlik-Skowronska B, Di Toppi LS, Corradi MG 2004. Cadmium tolerance, cysteine and thiol peptide levels in wild type and chromium-tolerant strains of Scenedesmus acutus(Chlorophyceae). Aquat Toxicol 68: 315-323.

27. Xiang C, Werner BL, Christensen EM, Oliver DJ. 2001. The biological functions of glutathione revisited in arabidopsis transgenic plants with altered glutathione levels. Plant Physiol 126: 564-574.

28. Vatamaniuk OK, Mari S, Lu Y, Rea PA. 2000. Mechanism of heavy metal ion activation of phytochelatin (PC) synthase. J Biol Chem 275: 31451-31459.

29. Briat JF, Lebrun M. 1999. Plant responses to metal toxicity. C R Acad Sci Ser III Sci Vie 322: 43-54.

30. Okamoto OK, Pinto E, Latorre LR, Bechara JH, Colepicolo P 2001. Antioxidant modulation in response to metal-induced oxidative stress in algal chloroplasts. Arch Environ Contam Toxicol 40: 18-24.

31. Schafer HJ, Greiner S, Rausch T, Haag-Kerwer A. 1997. In seedlings of the heavy metal accumulatorBrassica juncea $\mathrm{Cu}^{2+}$ differentially affects transcript amounts for $\gamma$ glutamylcysteine synthetase ( $\gamma$-ECS) and metallothionein (MT2). FEBS Lett 404: 216220.

32. May MJ, Vernoux T, Leaver C, Montagu MV, Inzé D. 1998. Glutathione homeostasis in plants: Implications for environmental sensing and plant development. $J$ Exp Bot 49: 649-667.

33. Noctor G, Arisi ACM, Jouanin L, Kunert KL, Rennenberg H, Foyer CH. 1998. Glutathione: Biosynthesis, metabolism, and relationship to stress tolerance explored in transformed plants. J Exp Bot 49: 623-647.

34. Chen J, Goldsbrough PB. 1994. Increased activity of $\gamma$-glutamylcysteine synthetase in tomato cells selected for cadmium tolerance. Plant Physiol 106: 233-239. 
35. Zhu YL, Pilon-Smits EAH, Tarun AS, Weber SE, Jouanin L, Terry N. 1999. Cadmium tolerance and accumulation in Indian mustard is enhanced by overexpressing $\gamma$ glutamylcysteine synthetase. Plant Physiol 121: 1169-1177.

36. Mehra RK, Winge DR. 1988. Cu(I) binding to the Schizosac-charomyces pombe $\gamma$ glutamyl peptides varying in chain length. Arch Biochem Biophys 265: 381-389.

37. Meuwly P, Thibault P, Schwan AL, Rauser WE. 1995. Three families of thiol peptides are induced by cadmium in maize. Plant $J$ 7: 391-400.

38. Kubota H, Sato K, Yamada T, Maitani T. 1995. Phytochelatins (class III metallothioneins) and their desglycyl peptides induced by cadmium in normal root cultures of Rubia tinctorum L. Plant Sci (Limerick)106: 157-166.

39. Ahner BA, Morel FMM. 1995. Phytochelatin production in marine algae. 2. Induction by various metals.Limnol Oceanogr 40: 658-665.

40. Morelli E, Scarano G 2001. Synthesis and stability of phytochelatins induced by cadmium and lead in the marine diatom Phaeodactylum tricornutum. Mar Environ Res 52: 383-395. 